\title{
Mindfulness-based social cognition training (SocialMIND) versus psychoeducational multicomponent intervention for people with a first episode of psychosis: a study protocol for a randomised controlled trial
}

\author{
Roberto Mediavilla $a^{1,2^{*}+}$ (D), Ainoa Muñoz-Sanjose ${ }^{1,3+}$, Beatriz Rodriguez-Vega ${ }^{1,3,4}$, Carmen Bayon ${ }^{1,3,4}$, Angela Palao ${ }^{1,3,4}$,
} Guillermo Lahera ${ }^{5,6}$, Pilar Sanchez-Castro ${ }^{1,3}$, Eva Roman ${ }^{1,3}$, Susana Cebolla1,3, Alvaro de Diego 1,3, Juan Manuel Pastor ${ }^{1,3}$ and Maria Fe Bravo-Ortiz ${ }^{1,3,4}$

\begin{abstract}
Background: People who suffer a first episode of psychosis experience higher levels of distress and suffering. Early intervention programs combine pharmacological and psychosocial strategies that include different components, such as cognitive-behavioural therapy, psychosocial interventions, medication adherence, family psychoeducation, counselling, etc. Among the complementary approaches, mindfulness-based interventions help participants to cultivate a radical acceptance of their psychotic experiences within a person-centered framework. They show promising results for people with longer duration of psychosis, but there is still no evidence for people who have recently experienced their first episode of psychosis.

Methods: The present parallel-group, single-blind (evaluator), randomised (1:1 ratio), controlled (versus active comparator), superiority, clinical trial will compare the effectiveness of SocialMIND on social functioning as measured by the Personal and Social Performance (PSP) scale. The active comparator will be a psychoeducational multicomponent intervention (PMI) that incorporates elements of early intervention programs that are effective for people who have suffered a first episode of psychosis. Both SocialMIND and PMI encompass eight weekly sessions, four bi-weekly sessions, and five monthly sessions. Changes in primary and secondary outcomes will be measured after weekly (8th week), bi-weekly (16th week) and monthly sessions (56th week), and 3 months after completing the intervention (68th week). Secondary outcomes include symptoms of psychosis, anxiety and depression, as well as indicators of general functioning. Tertiary outcomes are measures of social cognition, neurocognition, mindfulness, and indicators of inflammation and oxidative stress. A final sample of 80 participants is proposed to detect clinically significant differences in social functioning.

(Continued on next page)
\end{abstract}

\footnotetext{
* Correspondence: roberto.mediavilla@idipaz.es

${ }^{\dagger}$ Roberto Mediavilla and Ainoa Muñoz-Sanjose contributed equally to this

work.

${ }^{1}$ Psychiatry and Mental Health Group, Hospital La Paz Institute for Health

Research (IdiPAZ), Madrid, Spain

${ }^{2}$ National University of Distance Education (UNED), Madrid, Spain

Full list of author information is available at the end of the article
}

(c) The Author(s). 2019 Open Access This article is distributed under the terms of the Creative Commons Attribution 4.0 International License (http://creativecommons.org/licenses/by/4.0/), which permits unrestricted use, distribution, and reproduction in any medium, provided you give appropriate credit to the original author(s) and the source, provide a link to the Creative Commons license, and indicate if changes were made. The Creative Commons Public Domain Dedication waiver (http://creativecommons.org/publicdomain/zero/1.0/) applies to the data made available in this article, unless otherwise stated. 
(Continued from previous page)

Discussion: This is the first mindfulness-based social cognition training for people with psychosis. SocialMIND aims to generate changes in the real-life functioning of people who have experienced a first episode of psychosis, and to be at least as effective as a psychoeducational multicomponent program. Adherence to the interventions is a common problem among young people with psychosis, so several difficulties are anticipated, and some methodological issues are discussed.

Trial registration: The trial was registered in ClinicalTrials.gov in October 2018 (NCT03309475).

Keywords: Mindfulness, Social cognition, Social functioning, Real-life outcomes, Psychosis, Schizophrenia spectrum disorders, Psychological intervention

\section{Background}

People who suffer a first episode of psychosis (FEP) are frequently adolescents or young adults $[1,2]$ and the recovery rate is around $40 \%$ [3]. Optimising the treatment of FEP is a priority for mental health experts [4], and early intervention programs must combine both pharmacological and psychosocial strategies [5, 6]. These psychosocial components are medication review, treatment adherence, vocational or educational counselling, psychoeducation, social skills training, or cognitive behavioural therapy, among others. There are some ongoing studies in Denmark [7], Italy [8], the United Kingdom [9], and other countries in Europe and abroad $[10,11]$. The results are promising in terms of treatment discontinuation, hospitalisations, symptoms reduction, global functioning and quality of life, but there are still some concerns about their cost-effectiveness [12, 13].

Other, more focal, interventions such as cognitive behavioural therapy or family psychoeducation have also shown good results for FEP [14]. However, empirical evidence is still limited, and additional studies are welcomed [15]. The diagnosis-evidence-basedpractice symptom-reduction model might be far from the needs and realities of patients, as it considers the FEP as a mere indicator of a vulnerability to develop a given diagnosis; on the other hand, a framework that promotes an accommodation to living with mental vulnerabilities through building resilience in the social and existential domains might be more useful in the clinical practice [16]. Mindfulness-based interventions (MBIs) have increased exponentially over the past three decades and they are gathering empirical evidence for emotional distress in the general population [17], for medical conditions [18], and for psychiatric disorders such as anxiety, depression, addictive behaviour, and psychosis [19]. Mindfulness is defined as paying attention to the present moment, on purpose, and non-judgmentally [20]. To cultivate this ability, mindfulness trainees learn a series of informal practices and formal meditation techniques, and they are invited to share their experiences during the group sessions. Both a radical acceptance of the experience and the ability to disengage from it are two core mindfulness dimensions that develop with its practice, and they have been proposed as new ways of coping with suffering for people with psychosis [21]. There is limited evidence regarding the effectiveness of MBIs for people with FEP, and no randomised controlled trials have yet published their results. Recently, MacDougall and colleagues [22] have shown the Mindfulness Ambassador Program (MAP) to be acceptable and feasible in FEP, and they are now working on a multicentre, randomised controlled trial (Clinicaltrials.gov identifier NCT03143907) that compare MAP with a waiting list group. Another record by David L. Penn and colleagues compares the Integrated Coping and Awareness Training (I-CAT) with treatment as usual (identifier NCT03067311). Finally, one additional study by Yip Lai King compares Mindfulnessbased Cognitive Therapy (MBCT) versus a psychoeducation program in Hong Kong (NCT03501862).

Our team has designed an intervention named SocialMIND, a mindfulness-based social cognition training specifically designed for young people who have suffered an FEP recently. It addresses domains of social cognition that are affected in the FEP [23], such as mental state attributions, emotion recognition, and attributional biases, and integrates them within an acceptance- and mindfulness-based framework. Because these domains account for a significant portion of the variance in social functioning [24], an improvement of real-life outcomes might be expected. We present a protocol for a randomised, controlled trial that is sensitive to three important aspects of the literature on psychosis: first, our sample will be people who have suffered their FEP within the past 5 years; second, a psychoeducational multicomponent intervention (PMI) will be included as an active comparator; and lastly, the primary outcome measure will be personal and social performance. Both SocialMIND and PMI will encompass 8 weekly sessions, 4 bi-weekly sessions, and 5 monthly sessions, and the assessments will be performed after sessions $8,12,17$, and 3 months later. 


\section{Methods}

The aim of this study is to compare the changes in social functioning in a cohort of people who have suffered a first episode of psychosis (FEP) within the past 5 years. They will be assigned to either a mindfulness-based social cognition training (SocialMIND) or a psychoeducational multicomponent intervention (PMI). For that purpose, a parallel-group, single-blind (evaluator), randomised (1:1 ratio), controlled (versus active comparator), superiority, clinical trial will be implemented. The investigation will be conducted at La Paz University Hospital (Madrid, Spain) in accordance with SPIRIT 2013 [25, 26] and CONSORT 2010 [27] statements. The Research Ethics Committee of La Paz University Hospital approved the trial (identifier 4911) and the protocol is available in www.clinicaltrials.gov (identifier NCT03309475). The study is part of the project Environment and Genes in Schizophrenia (AGES-CM 2-CM) (http://www.agescm.es).

\section{Participants}

Eligible participants will be identified by any professional of the Department of Psychiatry, Clinical Psychology and Mental Health of La Paz University Hospital, as well as professionals from other centres of AGES-CM 2-CM. If the participant is already under treatment by a psychiatrist or a psychologist, the treating professional will be contacted to confirm eligibility criteria. The participants will be asked to maintain their treatment as usual with any mental health professional. In order to keep recruitment active, members of the study team will visit every unit of the Mental Health Department every month.

\section{Inclusion criteria}

1) Age between 18 and 45 years;

2) First hospitalization, first visit to mental health services with positive symptoms, onset of antipsychotic treatment, or first appearance of positive symptoms confirmed by an informant within the period of 5 years prior to enrolment in the study;

3) Signed Informed Consent form

\section{Exclusion criteria}

1) Other DSM-5 diagnosis, except for nicotine-related disorders and main diagnosis;

2) Clinical Global Impression higher than 5 ("markedly ill");

3) Intellectual disability plus impaired global functioning prior to disorder onset;

4) Generalised development disorder;

5) Pregnancy
6) Attendance at either mindfulness programs or structured psychoeducational interventions at the time of enrolment

\section{Withdrawal criteria}

1) Participant's decision;

2) Hospitalisation in a psychiatric unit;

3) Worsening clinical condition identified by the researchers or the participant's psychiatrist or psychologist;

4) Attendance at less than $25 \%$ of the sessions (less than three weekly-sessions, less than two fortnightly sessions, and less than two monthly sessions) ${ }^{1}$;

5) Attendance at either mindfulness programs or structured psychoeducational interventions during the trial

\section{Interventions}

\section{SocialMIND training}

SocialMIND is an intervention for people with psychosis designed by the authors. It is a mindfulness-based social cognition training that highlights the importance of cultivating an acceptance-based, non-judgmental approach both towards one's own experience and to the experience in the interpersonal relationship. It incorporates both formal meditation practices tailored for people with psychosis and sensitive to mental health vulnerabilities and suffering, as well as some social cognition exercises inspired by the Social Cognition and Interaction Training (SCIT) [28]. Practices of formal meditation are based on practices of three formal mindfulness programs: Mindfulness-Based Stress Reduction program (MBSR) [29], Mindfulness-Based Cognitive Therapy (MBCT) [30], and Mindful Self-Compassion program (MSC) [31]. Some of these practices consists of focusing attention on a chosen object either inside (i.e., breathing, body point contact, and body sensations) or outside (i.e., sounds) body scanner, walking meditation, or compassion practices such as loving kindness or soothing touch meditations. SocialMIND teachers are certified teachers of these programs, and recommendations on the adaptation of mindfulness programs for people with psychosis were cautiously looked into [21, 32]. Social cognition training includes attributional bias exercises, mentalising abilities (i.e., theory of mind), or emotion perception and social cues tasks. The full intervention consists of eight weekly sessions, followed by four bi-weekly sessions, and five additional monthly sessions. Each session lasts 90 min and groups are composed of a maximum of 15

\footnotetext{
${ }^{1}$ Participants could keep attending the groups if they wanted to and if the therapists agreed
} 
participants. The contents of SocialMIND sessions are shown in Table 1.

\section{Psychoeducational multicomponent intervention (PMI)}

PMI is a group intervention for people with a FEP that has been developed and standardised by the authors. It incorporates several components of multimodal early intervention programs with empirical support, such as psychoeducation for patients and for their families, medication review, vocational and educational counselling, crisis management and relapse prevention [13]. Two psychiatrists will lead the groups, but the program is well-structured and other mental health professionals such as psychologists, mental health nurses, or mental health residents can lead the PMI after some training. The full intervention consists of eight weekly sessions, followed by four bi-weekly sessions, and five additional monthly sessions. Each one lasts $90 \mathrm{~min}$ and groups are composed of a maximum of 15 participants. The weekly sessions (1st to 8th) focus on providing information about psychosis: signs and symptoms, possible underlying diagnosis, pharmacological treatments and their side effects, and psychosocial therapies. During biweekly sessions 9th to 12th and during monthly sessions 13th to 15th, participants and therapists design an individualised well-being plan focusing on self-care abilities, coping strategies and practice of social skills. In these sessions, an individual crisis management protocol is developed for each participant. Lastly, participants are asked to invite their family, friends, or any significant person to the two final sessions (16th and 17th), in order to give them information about psychosis and to empower them as key agents for a successful implementation of the well-being plan. Table 2 shows an example of one of the sessions.

The interventions SocialMIND and PMI will be scheduled in the evenings to reach participants who are studying or working in the morning; nonetheless, minor modifications will be made if consensus is achieved (e.g., start $10 \mathrm{~min}$ later so one participant can arrive on time). Two co-therapists will conduct the sessions and one research assistant will be in charge of sending reminders for each session (text messages or phone calls depending on the participant's preference). Although both interventions are standardised, some contents and practices of both programs might be modified based on clinical decisions (e.g., modify the duration of a formal meditation practice, adapt the content of a psychoeducational session to the period of time since the first episode of psychosis, etc.). In order to keep these minor protocol variations to a minimum, sessions will be video recorded to check if the professionals comply with the intervention manual.

\section{Outcomes and measurements}

Most outcomes will be measured at five time periods: before randomisation $\left(t_{0}\right.$, baseline), after weekly sessions $\left(t_{1}, 8\right.$ weeks), after bi-weekly sessions ( $t_{2}, 16$ weeks), after monthly sessions $\left(t_{3}, 36\right.$ weeks) and 12 weeks after end of the intervention ( $t_{4}, 48$ weeks). Weekly and bi-weekly sessions are the most intensive part of the treatment, whilst monthly sessions are booster sessions; thus, change between $t_{0}$ and $t_{2}$ is set as the main outcome across the different domains. Table 3 shows the participant's timeline.

\section{Baseline measures}

\section{Sociodemographic measures}

Age, gender, marital status, educational level, job status and parental level of education and parental job status will be codified.

\section{Clinical measures}

History of hospitalisations since the FEP, duration of untreated illness, duration of untreated psychosis, significant life events, and DSM-5 diagnosis will be registered. Other pharmacological and non-pharmacological interventions as well as current medication and psychosocial care will be checked.

\section{Primary outcome variable \\ Social functioning}

Change in social functioning between $t_{0}$ and $t_{2}$ will be measured using the Personal and Social Performance (PSP) [33] scale for schizophrenia. This scale explores four domains of social functioning, namely self-care, social relationships, social activities, and disruptive and aggressive behaviour. After the semi-structured interview, a final score (ranging from 1 to 100) is obtained, with higher values indicating better performance. The Spanish version of the PSP [34] is reliable and presents high internal consistency (Cronbach's alpha $=0.87$ ), and excellent testretest reliability $(r=0.98)$, and good construct validity (one single component explains $73 \%$ of the variance in social functioning). The mean of the PSP-T is 50.3 and the standard deviation is 18.6 points, with an increment of 15 points being considered clinically significant.

\section{Secondary outcome variables Social functioning}

Change in social functioning between $t_{0}$ and $t_{2}$, and between the remaining endpoints $\left(t_{1}, t_{3}\right.$ and $\left.t_{4}\right)$ will be assessed with the PSP. Changes from $t_{0}$ to $t_{2}$ in its final score are set as the primary outcome measure; changes between the remaining endpoints $\left(t_{1}, t_{3}\right.$ and $\left.t_{4}\right)$, and changes in subscales (self-care, social relationships, social activities, and disruptive and aggressive behaviour) are secondary outcome measures. Subscales provide 
Table 1 SocialMIND training overview

\begin{tabular}{|c|c|c|c|c|}
\hline Session & Didactic teaching & Practices & Exercises & Homework \\
\hline $\begin{array}{l}\text { \#1. Awareness of the present- } \\
\text { moment }\end{array}$ & $\begin{array}{l}\text { 1. Welcome and presenting to } \\
\text { the group: setting and } \\
\text { guidelines } \\
\text { 2. Introduction to mindfulness }\end{array}$ & $\begin{array}{l}\text { 1. 3-min meditation } \\
\text { on internal stimuli } \\
\text { (body, feelings, } \\
\text { emotions and } \\
\text { thoughts) } \\
\text { 2. Mindful } \\
\text { movements } \\
\text { (trainees perform a } \\
\text { series of } \\
\text { movements } \\
\text { performed with full } \\
\text { awareness) } \\
\text { 3. Shared inquiry: } \\
\text { group discussion }\end{array}$ & $\begin{array}{l}\text { Raisin exercise: eat a raisin with } \\
\text { full awareness }\end{array}$ & $\begin{array}{l}\text { Pay attention on daily activities } \\
\text { (eating, showering, household } \\
\text { chores...) }\end{array}$ \\
\hline \#2. Diversity in perception & $\begin{array}{l}\text { 1. Differences between } \\
\text { interpreting and describing } \\
\text { the experience. } \\
\text { 2. Stop before making } \\
\text { assumptions on other's } \\
\text { motivations or urges. }\end{array}$ & $\begin{array}{l}\text { 1. 3-min meditation } \\
\text { on internal stimuli } \\
\text { 2. Mindful } \\
\text { movements } \\
\text { 3. 3-min meditation } \\
\text { on breathing, feet, } \\
\text { hands or sounds } \\
\text { (anchor options) } \\
\text { 4. Shared inquiry }\end{array}$ & $\begin{array}{l}\text { 1. The storyteller (instructors } \\
\text { encourage participants to } \\
\text { become aware of the human } \\
\text { tendency to elaborate } \\
\text { narratives from events): } \\
\text { describing and interpreting a } \\
\text { drawing. } \\
\text { 2. STOP (instructors and } \\
\text { trainees work with this } \\
\text { acronym for Stop, Take a } \\
\text { breath, Observe and Proceed) }\end{array}$ & $\begin{array}{l}\text { 1. Pay attention on daily } \\
\text { activities } \\
\text { 2. STOP } \\
\text { 3. Attention on anchor } \\
\text { (breathing feet, hands or } \\
\text { sounds), when stress is present }\end{array}$ \\
\hline \#3. Coping with distress & $\begin{array}{l}\text { 1. How human beings } \\
\text { perceive, elaborate and } \\
\text { respond to their experiences } \\
\text { (pleasant, unpleasant and } \\
\text { neutral) } \\
\text { 2. The tendency to avoid } \\
\text { unpleasant experiences. }\end{array}$ & $\begin{array}{l}\text { 1. 5-min meditation } \\
\text { on body sensations, } \\
\text { thoughts and } \\
\text { sounds } \\
\text { 2. Walking } \\
\text { meditation } \\
\text { 3. Shared inquiry }\end{array}$ & $\begin{array}{l}\text { 1. Successive guided reflection } \\
\text { on pleasant and unpleasant } \\
\text { experiences } \\
\text { 2. STOP } \\
\text { 3. Dynamics: } \\
\text { a. Thoughts: The meditator (one } \\
\text { participant acts as someone } \\
\text { who is trying to meditate } \\
\text { whilst the others move around } \\
\text { him or her and act as } \\
\text { distracting thoughts) } \\
\text { b. Primary versus secondary } \\
\text { distress }\end{array}$ & $\begin{array}{l}\text { 1. Pay attention on daily } \\
\text { activities } \\
\text { 2. STOP } \\
\text { 3. Attention on anchor when } \\
\text { stress is present } \\
\text { 4. Walking meditation }\end{array}$ \\
\hline \#4. Radical acceptance & $\begin{array}{l}\text { 1. Acceptance of both pleasant } \\
\text { and unpleasant experiences is } \\
\text { different from resignation or } \\
\text { giving up. } \\
\text { 2. Each mental event shall be } \\
\text { understood as a product of } \\
\text { the mind }\end{array}$ & $\begin{array}{l}\text { 1. 5-min meditation } \\
\text { on internal stimuli } \\
\text { 2. Body scan (10 } \\
\text { min) } \\
\text { 3. Mindful } \\
\text { movements } \\
\text { 4. Yes/No } \\
\text { meditation } \\
\text { 5. Shared inquiry }\end{array}$ & $\begin{array}{l}\text { Emotion recognition in } \\
\text { photographs of people's faces: } \\
\text { differences between } \\
\text { describing a face and } \\
\text { elaborating a story. }\end{array}$ & $\begin{array}{l}\text { 1. Pay attention on daily } \\
\text { activities } \\
\text { 2. STOP } \\
\text { 3. Attention on anchor when } \\
\text { stress is present } \\
\text { 4. Walking meditation } \\
\text { 5. Guided practice (voice } \\
\text { recorded): } 5 \text {-min meditation on } \\
\text { internal stimuli; } 3 \text { and 5-min } \\
\text { meditation on breathing; body } \\
\text { scan }\end{array}$ \\
\hline $\begin{array}{l}\# 5 \text {. Unconditional friendship } \\
\text { and compassion }\end{array}$ & $\begin{array}{l}\text { Self-compassion and loving } \\
\text { kindness promote health and } \\
\text { wellbeing. The importance of } \\
\text { being aware of self-criticism } \\
\text { and judging attitudes toward } \\
\text { oneself and others. }\end{array}$ & $\begin{array}{l}\text { 1. 3-min meditation } \\
\text { on internal stimuli } \\
\text { 2. Soothing touch } \\
\text { meditation } \\
\text { 3. Mindful } \\
\text { movements (yoga } \\
\text { choices) } \\
\text { 4. Loving kindness } \\
\text { meditation } \\
\text { 5. Shared inquiry }\end{array}$ & $\begin{array}{l}\text { 1. The storyteller } \\
\text { 2. Emotion recognition in } \\
\text { photographs of people's faces: } \\
\text { differences between } \\
\text { describing a face and } \\
\text { elaborating a story. }\end{array}$ & $\begin{array}{l}\text { 1. Pay attention on daily } \\
\text { activities } \\
\text { 2. STOP } \\
\text { 3. Attention on anchor when } \\
\text { stress is present } \\
\text { 4. Walking meditation } \\
\text { 5. Guided practice (voice } \\
\text { recorded): } 5 \text {-min meditation on } \\
\text { internal stimuli; } 3 \text { and 5-min } \\
\text { meditation on breathing; body } \\
\text { scan; soothing touch } \\
\text { meditation; loving kindness } \\
\text { meditation }\end{array}$ \\
\hline \#6. Cultivate the wholesome & $\begin{array}{l}\text { Looking for pleasant } \\
\text { experiences in order to } \\
\text { balance the bias towards the }\end{array}$ & $\begin{array}{l}\text { 1. Body scan: special } \\
\text { attention to } \\
\text { pleasant sensations. }\end{array}$ & $\begin{array}{l}\text { 1. Looking for pleasant, nice, } \\
\text { beautiful objects, views, } \\
\text { sounds... in the room and }\end{array}$ & $\begin{array}{l}\text { 1. Pay attention on daily } \\
\text { activities } \\
\text { 2. STOP }\end{array}$ \\
\hline
\end{tabular}


Table 1 SocialMIND training overview (Continued)

\begin{tabular}{|c|c|c|c|c|}
\hline Session & Didactic teaching & Practices & Exercises & Homework \\
\hline & negative experiences. & $\begin{array}{l}\text { 2. Mindful } \\
\text { movements } \\
\text { 3. Loving kindness } \\
\text { meditation } \\
\text { 4. Shared inquiry }\end{array}$ & $\begin{array}{l}\text { savoring the experience (body } \\
\text { sensations, emotions, feelings, } \\
\text { thoughts...) } \\
\text { 3. The storyteller } \\
\text { 4. Emotion recognition in } \\
\text { photographs of people's eyes: } \\
\text { differences between } \\
\text { describing a face/ eyes and } \\
\text { elaborating a story. }\end{array}$ & $\begin{array}{l}\text { 3. Attention on anchor } \\
\text { (breathing feet, hands or } \\
\text { sounds), when stress is present } \\
\text { 4. Walking meditation } \\
\text { 5. Guided practice (voice } \\
\text { recorded): } 5 \text {-min meditation on } \\
\text { internal stimuli; } 3 \text { and 5-min } \\
\text { meditation on breathing; body } \\
\text { scan; soothing touch } \\
\text { meditation; loving kindness } \\
\text { meditation } \\
\text { 6. Looking for pleasant } \\
\text { experiences }\end{array}$ \\
\hline $\begin{array}{l}\text { \#7. Relationship and } \\
\text { connection }\end{array}$ & $\begin{array}{l}\text { 1. The connection. Human } \\
\text { beings are social beings and } \\
\text { we need to connect in a safe } \\
\text { environment with another } \\
\text { person. } \\
\text { 2. Pause when tension arises. } \\
\text { 3. Introduce the mindful } \\
\text { dialogue }\end{array}$ & $\begin{array}{l}\text { 1. Body scan } \\
\text { 2. Mindful } \\
\text { movements } \\
\text { 3. Loving kindness } \\
\text { meditation } \\
\text { 4. Shared inquiry }\end{array}$ & $\begin{array}{l}\text { 1. Interpersonal exercise of } \\
\text { loving kindness and } \\
\text { compassion } \\
\text { 2. Mindful dialogue } \\
\text { 3. Emotion recognition in } \\
\text { photographs of people's eyes: } \\
\text { differences between } \\
\text { describing a face/ eyes and } \\
\text { elaborating a story. }\end{array}$ & $\begin{array}{l}\text { 1. Pay attention on daily } \\
\text { activities } \\
\text { 2. STOP } \\
\text { 3. Attention on anchor when } \\
\text { stress is present } \\
\text { 4. Walking meditation } \\
\text { 5. Guided practice (voice } \\
\text { recorded): } 5 \text {-min meditation on } \\
\text { internal stimuli; } 3 \text { and 5-min } \\
\text { meditation on breathing; body } \\
\text { scan; soothing touch } \\
\text { meditation; loving kindness } \\
\text { meditation } \\
\text { 6. Looking for pleasant } \\
\text { experiences }\end{array}$ \\
\hline \#8. To live in balance & $\begin{array}{l}\text { 1. Equanimity: being able to } \\
\text { be with the pleasant and the } \\
\text { unpleasant experiences, } \\
\text { without pushing anything out } \\
\text { of consciousness } \\
\text { 2. Delivery of certificates: 8- } \\
\text { weeks SocialMind training } \\
\text { certificate }\end{array}$ & $\begin{array}{l}50 \text { min of } \\
\text { continuum practice: } \\
\text { 1. Body scan } \\
\text { 2. Walking } \\
\text { meditation } \\
\text { 3. Meditation on } \\
\text { anchor options } \\
\text { 4. Mindful } \\
\text { movements } \\
\text { 5. Soothing touch } \\
\text { meditation } \\
\text { 6. Loving kindness } \\
\text { meditation } \\
\text { Shared inquiry: } \\
\text { group discussion }\end{array}$ & $\begin{array}{l}\text { 1. The storyteller } \\
\text { 2. Emotion recognition in } \\
\text { photographs of people's eyes: } \\
\text { differences between } \\
\text { describing a face/ eyes and } \\
\text { elaborating a story. } \\
\text { 3. Letter to yourself: what you } \\
\text { have learned and what are } \\
\text { your proposals at the end of } \\
\text { the program }\end{array}$ & $\begin{array}{l}\text { 1. Pay attention on daily } \\
\text { activities } \\
\text { 2. STOP } \\
\text { 3. Attention on anchor } \\
\text { (breathing feet, hands or } \\
\text { sounds), when stress is present } \\
\text { 4. Walking meditation } \\
\text { 5. Guided practice (voice } \\
\text { recorded): } 5 \text {-min meditation on } \\
\text { internal stimuli; } 3 \text { and 5-min } \\
\text { meditation on breathing; body } \\
\text { scan; soothing touch } \\
\text { meditation; loving kindness } \\
\text { meditation } \\
\text { 6. Looking for pleasant } \\
\text { experiences }\end{array}$ \\
\hline $\begin{array}{l}\text { \#9-12. Consolidation sessions } \\
\text { and } \\
\# 12-15 \text {. Integration (in daily } \\
\text { life) sessions (Contents of } \\
\text { consolidation sessions in an } \\
\text { interactive way and } \\
\text { focalizing in participants' } \\
\text { choices) }\end{array}$ & $\begin{array}{l}\text { It emerges from the } \\
\text { experience of the participants } \\
\text { and is presented in an } \\
\text { interactive way: } \\
\text { 1. Emphasis on interpersonal } \\
\text { practice } \\
\text { 2. STOP } \\
\text { 3. Looking for pleasant } \\
\text { experiences } \\
\text { 4. Equanimity } \\
\text { 5. Friendship and compassion } \\
\text { towards connection with } \\
\text { myself and other beings } \\
\text { 6. Be aware of jumping to } \\
\text { conclusions (stories) }\end{array}$ & $\begin{array}{l}\text { Possibilities: } \\
\text { 1. Meditation on } \\
\text { internal stimuli } \\
\text { (body, feelings, } \\
\text { emotions and } \\
\text { thoughts) } \\
\text { 2. Breathing } \\
\text { meditation } \\
\text { 3. Walking } \\
\text { meditation } \\
\text { 4. Meditation on } \\
\text { breathing, feet, } \\
\text { hands or sounds } \\
\text { (anchor options) } \\
\text { 5. Body scan } \\
\text { 6. Mindful } \\
\text { movements } \\
\text { 7. Soothing touch } \\
\text { meditation } \\
\text { 8. Loving kindness } \\
\text { meditation } \\
\text { Shared inquiry }\end{array}$ & $\begin{array}{l}\text { 1. Interpersonal sharing of } \\
\text { experiences } \\
\text { 2. Emotion recognition in } \\
\text { people's faces (group's } \\
\text { couples): differences between } \\
\text { describing a face and } \\
\text { elaborating a story. }\end{array}$ & $\begin{array}{l}\text { 1. Pay attention on daily } \\
\text { activities } \\
\text { 2. STOP } \\
\text { 3. Attention on anchor } \\
\text { (breathing feet, hands or } \\
\text { sounds), when stress is present } \\
\text { 4. Walking meditation } \\
\text { 5. Guided practice (voice } \\
\text { recorded): } 5 \text {-min meditation on } \\
\text { internal stimuli; } 3 \text { and 5-min } \\
\text { meditation on breathing; body } \\
\text { scan; soothing touch } \\
\text { meditation; loving kindness } \\
\text { meditation } \\
\text { Looking for pleasant } \\
\text { experiences }\end{array}$ \\
\hline
\end{tabular}


Table 2 Psychoeducational multicomponent intervention: Contents of session 2 ("Understanding psychosis")

\begin{tabular}{|c|c|c|c|}
\hline Structure & Contents & Dynamics & Duration \\
\hline Welcome and small talk & Small talk about the week & Conversation & $10 \mathrm{~min}$ \\
\hline Summary of the previous session & $\begin{array}{l}\text { Group setting and norms; } \\
\text { overview of Mental Health Services in the } \\
\text { Region of Madrid; } \\
\text { questions and comments }\end{array}$ & Oral exposition & $20 \mathrm{~min}$ \\
\hline Presentation of the topic of the session & $\begin{array}{l}\text { 1. What is psychosis. Signs and symptoms } \\
\text { 2. The diathesis-stress model: risk and } \\
\text { protective factors } \\
\text { 3. The phases of the psychotic process }\end{array}$ & Oral exposition. Q\&A & $40 \mathrm{~min}$ \\
\hline Questions, comments and debate & $\begin{array}{l}\text { Participants are invited to express their } \\
\text { doubts about the topic and to share } \\
\text { any experience related to it }\end{array}$ & Conversation. Q\&A & $20 \mathrm{~min}$ \\
\hline Closure & $\begin{array}{l}\text { Brief summary of the session } \\
\text { Brief introduction to the next session } \\
\text { Homework }\end{array}$ & Oral exposition. Distribution of materials & $10 \mathrm{~min}$ \\
\hline
\end{tabular}

ordinal data that range from "absent" to "very severe", with higher values indicating worse performance.

\section{General functioning}

Change in general functioning between $t_{0}$ and $t_{2}$, and between the remaining endpoints $\left(t_{1}, t_{3}\right.$ and $\left.t_{4}\right)$ will be assessed with the General Assessment of Functioning (GAF) $[35,36]$ scale. It provides a score from 1 to 100 , with higher values indicating better general functioning. It has good inter-rater reliability and is also associated with symptoms and social functioning in people with schizophrenia [37]. The evaluator completes this scale after a semi-structured interview exploring clinical and functional outcomes.

\section{Positive and negative syndrome}

Change in positive and negative symptoms, and in general psychopathology, between $t_{0}$ and $t_{2}$, and between the remaining endpoints $\left(t_{1}, t_{3}\right.$ and $\left.t_{4}\right)$, will be assessed with Positive and Negative Syndrome Scale (PANSS) [38] for schizophrenia. Values range from 1 ("absent") to 7 ("extreme"), and final scores range from 7 to 49 for positive (PANSS-P) and negative (PANSS-N) syndromes, and from 16 to 112 for general psychopathology. A semi-structured interview is conducted to rate each dimension. Subscales of Spanish version are strongly associated with the original version ( $r=0.92$ for PANSS-P and $r=0.83$ for PANSS-N), with item correlations ranging from $r=0.64$ to $r=0.97$ and high inter-rater reliability $(r=0.81)$ [39].

\section{Depressive symptoms}

Change in depressive symptoms between $t_{0}$ and $t_{2}$, and between the remaining endpoints $\left(t_{1}, t_{3}\right.$ and $\left.t_{4}\right)$, will be assessed with Calgary Depression Scale for Schizophrenia (CDSS) [40]. A semi-structured interview is conducted and a final score between 0 and 36 is obtained, with lower values indicating fewer symptoms. Spanish version of CDSS has high internal consistency (Cronbach's alpha = 0.83 ) and high inter-rater reliability (ICC >0.70); it also discriminates between depressed and non-depressed people with SSD [41].

\section{Anxiety symptoms}

Change in anxiety symptoms between $t_{0}$ and $t_{2}$, and between the remaining endpoints $\left(t_{1}, t_{3}\right.$ and $\left.t_{4}\right)$, will be assessed with self-reported Beck Anxiety Inventory (BAI) [42]. It is a 21-item scale and participants rate how affected have they be by a list of anxiety symptoms during the last week in a 0 to 3 Likert scale. Scores range between 0 (minimum, no anxiety) and 84 (maximum, extreme anxiety). Spanish version [43] has high internal consistency (Cronbach's alpha $=0.90$ ) and discriminates between people with and without anxiety disorders $[43,44]$.

\section{Screening of bipolar disorder}

Change in manic and depressive symptoms between $t_{0}$ and $t_{2}$, and between the remaining endpoints $\left(t_{1}, t_{3}\right.$ and $t_{4}$ ), will be rate by the assessor with Clinical Global Impression for Bipolar Disorder (CGI-BD) [45]. Two Likert scales rate depressive and manic symptoms in the last week, ranging from 1 ("normal") to 7 ("extreme"); one additional 7-points Likert scale evaluates general severity in the last year. It is better than the original CGI for the assessment of bipolar disorder and has good inter-rater reliability [45]. Scores are based on the assessor's clinical impression after a semi-structured interview.

\section{Adverse events}

Visits to the emergency room, hospitalizations, and treatment discontinuation will be registered in detail from baseline to the end of the study. 
Table 3 Participant's timeline

\begin{tabular}{|c|c|c|c|c|c|c|}
\hline \multirow{3}{*}{$\overline{\text { Timepoint }}$} & \multicolumn{6}{|c|}{ Study period } \\
\hline & \multirow{2}{*}{$\begin{array}{l}\text { Enrolment } \\
\mathrm{t}_{-1}\end{array}$} & \multirow{2}{*}{$\begin{array}{l}\text { Allocation } \\
0\end{array}$} & \multicolumn{3}{|c|}{ Post-allocation } & \multirow{2}{*}{$\begin{array}{l}\text { Close-ou } \\
t_{4}\end{array}$} \\
\hline & & & $t_{1}$ & $\mathrm{t}_{2}$ & $t_{3}$ & \\
\hline \multicolumn{7}{|l|}{ Enrolment } \\
\hline Eligibility screen & $x$ & & & & & \\
\hline Informed consent & $x$ & & & & & \\
\hline Allocation & & $x$ & & & & \\
\hline \multicolumn{7}{|l|}{ Interventions } \\
\hline SocialMIND & & & w & B & M & \\
\hline PMl & & & W & B & M & \\
\hline \multicolumn{7}{|l|}{ Assessments } \\
\hline Baseline & $x$ & & & & & \\
\hline \multicolumn{7}{|l|}{ Demographic } \\
\hline \multicolumn{7}{|l|}{ Duration of untreated illness } \\
\hline \multicolumn{7}{|l|}{ Duration of untreated psychosis } \\
\hline \multicolumn{7}{|l|}{ Number of hospitalizations } \\
\hline \multicolumn{7}{|l|}{ Diagnosis } \\
\hline \multicolumn{7}{|c|}{ Psychosocial and pharmacological treatment } \\
\hline Functional outcomes & $x$ & & $x$ & $x$ & $x$ & $x$ \\
\hline \multicolumn{7}{|l|}{ Social functioning } \\
\hline \multicolumn{7}{|l|}{ General functioning } \\
\hline Clinical outcomes & $x$ & & $x$ & $x$ & $x$ & $x$ \\
\hline \multicolumn{7}{|l|}{ Positive syndrome } \\
\hline \multicolumn{7}{|l|}{ Negative syndrome } \\
\hline \multicolumn{7}{|l|}{ General psychopathology } \\
\hline \multicolumn{7}{|l|}{ Depressive symptoms } \\
\hline \multicolumn{7}{|l|}{ Anxiety symptoms } \\
\hline \multicolumn{7}{|l|}{ Adverse events } \\
\hline Biological outcomes & $x$ & & & $x$ & $x$ & \\
\hline \multicolumn{7}{|l|}{ Cytokines } \\
\hline Antioxidant status & & & & & & \\
\hline Oxidative/nitrosative stress & & & & & & \\
\hline Social cognition outcomes & $x$ & & & $x$ & $x$ & \\
\hline Theory of mind & & & & & & \\
\hline Attributional style & & & & & & \\
\hline Emotion recognition & & & & & & \\
\hline Cognitive outcomes & $x$ & & & $x$ & $x$ & \\
\hline Processing speed & & & & & & \\
\hline Working memory & & & & & & \\
\hline Vigilance & & & & & & \\
\hline Emotional intelligence & & & & & & \\
\hline Other outcomes & $x$ & & $x$ & $x$ & $x$ & \\
\hline Mindful attention and awareness & & & & & & \\
\hline Adherence to SocialMIND manuala & & & & & & \\
\hline
\end{tabular}

PMI psychoeducational multicomponent intervention, $W$ weekly sessions, $B$ bi-weekly sessions, $M$ monthly sessions ${ }^{a}$ Only from $t_{1}$ to $t_{3}$

\section{Tertiary outcome variables}

\section{Social cognition (mental state attribution)}

Change in theory of mind between $t_{0}$ and $t_{2}$, and between the remaining endpoints $\left(t_{1}, t_{3}\right.$ and $\left.t_{4}\right)$, will be assessed with the 5 -item version of the Hinting Task $[46,47]$ and with the revised version of Eyes Test $[48,49]$. The Hinting Task consists of five stories where a character insinuates that he or she wants the other to do something. The assessor reads the situations out loud to the participant, whose response is written down literally. Scores range from 2 to 
0 points for each item, and final score ranges from 0 (worst performance), to 10 (best performance). Internal consistency (Cohen's alpha $=0.78$ ), test-retest stability (Cohen's kappa $=0.83$ ), and inter-rater reliability (Cohen's kappa $=0.94)$ are good in the Spanish version, which accurately discriminates between people with schizophrenia and healthy controls [50]. The revised version of the Eyes Test comprises 36 pictures of the eyes area expressing different emotions, so it recruits emotion recognition abilities as well [51]. There are four response options for each item and only one of them is correct. One point is given for each correct response, so final score ranges from 0 to 36. It has been adapted to Spanish population with a good test-retest reliability $(\mathrm{ICC}=0.76)$ [52].

\section{Social cognition (emotion recognition)}

Change in emotion recognition between $t_{0}$ and $t_{2}$ and between the remaining endpoints $\left(t_{1}, t_{3}\right.$ and $\left.t_{4}\right)$, will be assessed with the Penn Emotion Recognition Test (ER-40) [53] consisting of 40 pictures of actors and actresses performing facial expressions for different basic emotions. Participants are always given the same five response options: happy, sad, anger, fear, and no emotion. A Spanish version is not available, and translation of the emotions' names matched the translation of a similar task [54].

\section{Social cognition (attributional style)}

Change in attributional style between $t_{0}$ and $t_{2}$, and between the remaining endpoints $\left(t_{1}, t_{3}\right.$ and $\left.t_{4}\right)$ will be assessed with the Ambiguous Intentions Hostility Questionnaire (AIHQ) [55]. Participants read fifteen stories that are either accidental, intentional, or uncertain (i.e., "you walk past a bunch of teenagers at a mall and you hear them start to laugh"). After reading each one of the stories, they are asked the following questions: a) why did the character do what he or she did?, b) did he or she do that on purpose?, c) how angry does it make you feel?, d) would you blame the character?, e) what would you do if you were in that situation? In items a) (hostility bias) and e) (aggression bias), participants are asked to write down their responses, which will be scored by two independent evaluators according to AIHQ scoring criteria; for item b) (intention index), a six-point Likert scale is provided; for items c) (blame index) and d) (anger index), a five-point Likert scale is provided. Five different indexes and one extra compound score are obtained. It is not adapted to the Spanish population.

\section{Mindful attention and awareness}

Change in mindful attention and awareness between $t_{0}$ and $t_{2}$, and between the remaining endpoints $\left(t_{1}, t_{3}\right.$ and $t_{4}$ ), will be assessed with the Mindful Attention and Awareness Scale (MAAS) [56]. It is a self-reported measure of mindful disposition and its scores range from 0 to 90 , with higher values indicating that the individual is more disposed to be aware and pay attention. The Spanish version has good internal consistency (Cohen's alpha $=0.89$ ) and high temporal stability $(r=0.823)$, with low sensitivity to change after mindfulness trainings $(r=0.79)$ [57].

\section{Neurocognition}

Change in neurocognition between $t_{0}$ and $t_{2}$, and between the remaining endpoints $\left(t_{1}, t_{3}\right.$ and $\left.t_{4}\right)$, will be assessed with five tasks of the Matrics Consensus Cognitive Battery (MCCB) [58]. Specifically, we included one processing speed index (Brief Assessment of Cognition in Schizophrenia: Symbol Coding [BACS]); four vigilance indexes of Continuous Performance Test - Identical Pairs (CPT-IP); and one verbal (Letter and Number Span [LNS]) and one visuospatial (Wechsler Memory Scale: Spatial Span [WMS-SS]) working memory tasks. Additionally, MCCB includes the Managing Emotions task of the Mayer-Salovey-Caruso Emotional Intelligence Test (MSCEIT). Standardized scores will be obtained through international MCCB scoring software, corrected for age, gender, and educational level.

\section{Biological outcomes}

Change in cytokines (IL1 $\beta$, IL6 y TNF $\alpha$ ), antioxidant status (TAS, CAT, SOD, GPx), and indicators of oxidative/ nitrosative stress (TBARS) will be assessed between $t_{0}$ and $t_{2}$, and between $t_{0}$ and $t_{3}$. Specific assay kits will be used.

\section{SocialMIND teachers' checklist}

This instrument consists of two parts. The first is inspired by the assessment of protocol compliance in Social Cognition and Interaction Training (SCIT) [28]. Raters must check if the teachers adhere to the SocialMIND manual and complete 8 items that range from 0 to 2 points, with higher values indicating more adherence. The second part is the Mindfulnessbased Interventions: Teaching Assessment Criteria (MBI:TAC) [59], which comprises six domains that should be addressed in each session, such as embodiment of mindfulness, correct guidance, or holding the group environment. Teachers can obtain a score between 1 ("Incompetent: Absence of key features or highly inappropriate performance") and 6 points ("Advanced: Excellent teaching practice, or very good even in the face of participant difficulties"). Assessments were made after checking video recordings of the sessions. 


\section{Psychoeducational multicomponent intervention checklist}

This instrument is also inspired in the assessment protocol of compliance to the SCIT, and the evaluators must complete 8 items that range from 0 to 2 points, with higher values indicating more adherence [28].

\section{Assessment procedure}

The assessment will be separated into two or three sessions according to the participant's preference. If the participant wants to divide the assessment in two sessions, blood tests and clinical measures, will be performed in the first appointment, and neurocognition and social cognition tasks in the second appointment. If the participant prefers to divide the assessment in three sessions, the first one will consist of blood tests and clinical measures, the second one will be the social cognition battery, and the last one will be the neurocognitive assessment. Morning and evening appointments will be available so participants can choose which one fits them better. For neurocognition tasks, if the baseline assessment is made in the morning, upcoming appointments will also be scheduled in the morning (in case of a baseline assessment in the evening, subsequent appointments will be made in the evening).

\section{Assignment of interventions}

Participants will receive a unique AGES-Mind identifier (e.g., AM-99) that will ensure his or her anonymity during the trial. The day before the interventions start, a research assistant will perform randomisation using TeamMaker ${ }^{\mathrm{TM}}$, a free software available from http://chir.ag/projects/team-maker/. Participants' identifiers will be introduced, and two teams will be formed (SocialMIND and PMI). A .cSV file with treatment allocation will be obtained and sent to the therapists, and the research assistant will call the participants and inform them about treatment allocation.

Such different behavioural interventions do not permit to mask the allocation for neither the research assistant, nor the therapists, or the participants; but the outcomes evaluator and data analyst will be blind to treatment allocation. It is difficult to ensure masking for a clinical trial that lasts a whole year, so the evaluators will not be responsible for contacting participants to perform the assessments; instead, they will be waiting for the participants in a room, and the participants will be advised twice about the importance of not revealing intervention assignment. For biological variables, the nurse performing the extraction will be blind to treatment assessment, but he will be assisted by a researcher who will not be. Materials for blood samples will not contain any information that reveals treatment allocation. Data analysts will receive a database with a dichotomous variable called "intervention arm" with two values ("1" and " 2 ") that will be randomly chosen too.

If unblinding happened to one of the evaluators, he or she will inform one of the leading investigators and the assessment will be repeated by another evaluator. The non-blind evaluator will not evaluate this participant again.

\section{Data collection, sample size calculation and statistical analysis}

Different evaluators will collect the data across the time points with the supervision of two research assistants and the two lead investigators. Evaluators will attend at least 1 day of training to become familiarised with the instruments, especially the rating scales and the neurocognitive battery. For self-reported measures (e.g., questionnaires, inventories) there will be no specific training. The research assistant in charge of data entry will check for any queries and solve them with the evaluator; then the assistant will enter data into the database, and ranges will be checked for each variable to detect possible errors. Database will be stored in a private server and in a hard disk in La Paz University Hospital. Participants who stop coming to the sessions will be asked to attend an assessment session and primary and secondary outcome data will be collected. They will be contacted again when it is time for the assessment in order to reduce missing data; in case they are not available or decide not to come, the last observation will be carried forward to the remaining time points.

For the primary outcome measure, an analysis of covariance (ANCOVA) will be performed to explore differences between the two interventions in the final score of the Personal and Social Performance Scale (PSP-T) after bi-weekly sessions $\left(t_{2}\right)$. PSP-T baseline score $\left(t_{0}\right)$ will be introduced as a covariate in the ANCOVA model. A 15-point increment is considered clinically significant [24] and corresponds to a moderate effect size (Cohen's $\mathrm{f}=.40$ ). In order to detect a change from $t_{0}$ to $t_{2}$ with a $90 \%$ of probability $(1-\beta=0.90)$ and a type I error of $5 \%$ $(\alpha=0.05), 68$ participants should enrol in the trial. Considering an attrition rate around $15 \%$, a final sample of 80 participants would be needed.

Goodness of fit indexes will be obtained to explore the distribution of all variables. Baseline demographic characteristics, biological outcomes, clinical variables, and cognitive scores will be assessed to test if groups are equivalent: $\mathrm{t}$-tests will be used for interval and ratio variables, Mann-Whitneys U test for ordinal variables, and Pearson's chi-squared tests for nominal variables. Missing values will be imputed with the last observation carried forward (LOCF) method. Intervention effects over interval and ratio variables will be assessed with a 2 
(Intervention arms: PMI, SocialMIND) $\times 5\left(\right.$ Time: $t_{0}, t_{1}$, $t_{2}, t_{3}, t_{4}$ ) ANCOVA, with baseline observation $\left(t_{0}\right)$ introduced as a covariate for $t_{1}$ and $t_{2}$, and the previous timepoint for $t_{3}\left(t_{2}\right.$ as a covariate) and for $t_{4}\left(t_{3}\right.$ as a covariate). Outcomes will be explored to check for violations of any ANCOVA assumptions. For dichotomous or dichotomised variables, number needed to treat (NNT) and risk ratios will be provided. Data will be analysed following a modified intention-to-treat model which will exclude participants who attend less than 3 weekly-sessions because they cannot be considered to have received the intervention. Standard intention-to-treat and per-protocol analyses will also be reported. Two-tailed tests will be carried out with alfa set at 0.05 . Data will be introduced in the database by a research assistant with knowledge of treatment allocation and analysed by a statistician blind to treatment allocation.

\section{Monitoring}

Risk of harm needs to be monitored during a clinical trial. The Research Ethics Committee will receive a report either once a year -if no adverse effects are detected-, or immediately -if any adverse event is detected. Moreover, only participants who are referred by their psychiatrists or psychologists are enrolled, so feedback mechanisms will be implemented between the professionals and the study team (e.g., e-mails, phone calls, visits, etc.). Evaluators will also ask for any adverse event detected since the previous visit.

One important risk of bias might happen when the study team decides to conclude the trial. Solutions such an external endpoint adjudication committee have been proposed. For our study, we have performed an a-priori sample size calculation, which has been made public in www.ClinicalTrials.gov and in this paper. Interim analyses will be performed, but they will not condition the decision to terminate the trial. Moreover, this protocol is being funded by the European Regional Development Fund (ERDF) and monitored by a panel of experts of the Institute of Health Carlos III (ISCIII) (identifier PI 17/00768).

One last point of great importance for behavioural interventions is the compliance with the intervention protocol. As described above, adherence to SocialMIND and PMI intervention manual will be monitored, and sessions will be recorded.

\section{Ethics and dissemination}

The study was approved by the Research Ethics Committee of La Paz University Hospital, with the identifier 4911. Three amendments were made before final approval. Every participant will sign two informed consents; the first one includes general aspects of the investigation and session video recordings, and the second one is specific for biological samples. These biological samples will be registered, processed and stored in the Hospital La Paz-IdiPAZ Biobank. All the information provided by the participants will be codified twice: the first code will identify every outcome variable (including biological outcomes), and the second one will be provided by the Biobank and will be exclusive for biological variables. Datasheets will not include the name, the surname or the address of any of the participants. The correspondence between participants' identifier and their personal data will be codified in a data spreadsheet file which will be stored by duplicate: one copy in a Network Attached Storage (NAS) of the Madrilenian Department of Health and the other in an external hard disk in a private office of La Paz University Hospital. Backups of video recordings will be made after each session and will be stored in this hard disk; then, the file will be erased from the camera. Participants will also be offered to participate in the group to which they have not been assigned after study completion $\left(t_{4}\right)$. Results will be made public in www.clinicaltrials.gov and in scientific communications (conferences, articles, posters, presentations...), and priority will be given to open-access journals. A final plain-language report will be given to each participant who is interested, and to the professionals who refer participants. The dataset supporting the conclusions of the randomised controlled trial will be available from the corresponding author on request.

\section{Discussion}

We present the study protocol for a randomised controlled trial that explores the effectiveness of SocialMIND, the first mindfulness-based social cognition group training developed for people with psychosis. Both SocialMIND and the psychoeducational multicomponent intervention (PMI) that serves as an active comparator have an intensive phase of 16 weeks -with 8 weekly sessions followed by 4 bi-weekly sessions-, and an extensive phase of 20 weeks with 5 monthly sessions.

Manualised Mindfulness-based interventions (MBI) such as the Mindfulness-based Stress Reduction program (MBSR) or the Mindfulness-based Cognitive Therapy (MBCT) lasts 8 weeks; however, people with higher levels of suffering and severe symptoms might benefit from longer programs. Hence, although primary and secondary outcomes will be measured after weekly sessions $\left(t_{1}\right)$, our hypothesis is that the training will be effective after completing the whole intensive phase $\left(t_{2}\right)$, so statistical analysis for our primary hypothesis will consider the change from baseline $\left(t_{0}\right)$ to $t_{2}$. An additional period of five monthly sessions is proposed in order to tests if changes are maintained, so exploring the difference between the time point 
after monthly sessions $\left(t_{3}\right)$ and $t_{2}$ will be of great interest.

The main obstacle of the study will be the recruitment of the 80 participants. This a priori sample size calculation is based on the Spanish validation of the Personal and Social Performance (PSP) scale, but the variability of our scores -and hence the required sample size- might be lower as our group will be more homogeneous in terms of duration of the illness, age, diagnosis, etc. There are many problems inherent in the use of patient-reported outcome measures (PROM) in clinical trials [60], but social functioning is a domain hardly measurable with instruments that are not self-reported; considering this, our study will adhere to the SPIRIT guidelines extension to PROM [26]. Moreover, the DELTA (Difference Elicitation in TriAls) project proposes that the primary outcome should be of relevance to at least one key stakeholder group [61], and improvements in social functioning are indeed crucial for patients, health professionals, and the Administration, as it is directly associated with real-life outcomes. In the case that social functioning would indeed increase after the intervention, a moderator analysis which incorporates different measures of social cognition and neurocognition would be of great interest. As we are conservative with our sample size estimation, these factors will only be explored as tertiary outcomes, leaving further analysis for upcoming investigations.

Our goal is ambitious. First, we expect to improve real-life outcomes, which is far more difficult than proving a reduction of symptoms or an increase of social cognition scores; second, we expect this improvement to be equal to or higher than the improvement in the active comparator arm; and lastly, we will include a cohort of people who rarely adhere to therapeutic programs [5]. Regardless of these difficulties, a patient-centered intervention such as SocialMIND may help young people who have suffered a FEP to create unique, meaningful narratives of their experience, and to disengage from it and the suffering that it entails. In the words of Rufus May, "if we are able to achieve some detachment from our beliefs in the knowledge they are just one way of seeing the world, we become more aware that 'the map' (i.e. our beliefs) is not the territory; and that different maps tell us about different aspects of the territory. It seems helpful to adopt a relational perspective towards our beliefs, thoughts and perceptions so that we both detach from them and try to relate to them" [62].

\section{Abbreviations}

AGES-CM 2-CM: Ambiente y Genes en Esquizofrenia - Comunidad de Madrid [Genes and Environment in Schizophrenia - Region of Madrid]; AlHQ: Ambiguous Intentions Hostility Questionnaire; ANCOVA: Analysis of Covariance; BACS: Brief Assessment of Cognition in Schizophrenia; BAl: Beck
Anxiety Inventory; CAT: Catalase; CDSS: Calgary Depression Scale for Schizophrenia; CGI-BD: Clinical Global Impression for Bipolar Disorder; CPTIP: Continuous Performance Test - Identical Pairs; DELTA: Difference Elicitation in TriAls; ER-40: Emotion Recognition Test; ERDF: European Regional Development Fund; FEP: First episode of psychosis; GAF: General Assessment of Functioning; GPx: Glutathione perioxidase; I-CAT: Integrated Coping and Awareness Training; IdiPAZ: Instituto de Investigación Sanitaria del Hospital Universitario La Paz [Hospital La Paz Institute for Health Research]; IL: Interleukin; ISCIII: Instituto de Salud Carlos III [Institute of Health Carlos III]; LNS: Letter and Number Span; MAAS: Mindful Attention and Awareness Scale; MAP: Mindfulness Ambassador Program; MBCT: Mindfulness-Based Cognitive Therapy; MBI:TAC: Mindfulness-Based Interventions: Teaching Assessment Criteria; MBSR: Mindfulness-Based Stress Reduction program; MCCB: MATRICS Consensus Cognitive Battery; MSC: Mindful Self-Compassion program; MSCEIT: Mayor-Salovey-Caruso Emotional Intelligence Test; NAS: Network Attached Storage; NNT: Number needed to treat; PANSS: Positive and Negative Syndrome Scale for Schizophrenia; PMI: Psychoeducational multicomponent program; PROM: Patient-reported outcome measures; PSP: Personal and Social Performance scale; SCIT: Social Cognition and Interaction Training; SOD: Superoxide dismutase; TAS: Total antioxidant status; TBARS: Thiobarbituric and reactive substances; TNF: Tumor necrosis factor; WMS-SS: Wechsler Memory Scale - Spatial Span

\section{Acknowledgements}

We thank MP Vidal-Villegas for her help in the development of the research project and the ERDF and the ISCIII for funding the research project (PI17/ 00768).

\section{Authors' contributions}

RM and AM-S wrote the manuscript. AM-S, BR-V, CB, AP and GL developed and standardised SocialMIND and helped with the sections about mindfulness and social cognition. PS, ER, SC, JMP and AD developed and standardised the psychoeducational multicomponent intervention and helped with the sections about early intervention in psychosis. MFB-O supervised the project and the writing of the manuscript. All authors have read and approved the manuscript.

\section{Funding}

The study is funded by the European Regional Development Fund (ERDF), which contributes with $87.500 €$ to the acquisition of goods and services. The Institute of Health Carlos III (ISCIII) peer-reviewed the study protocol and monitors the implementation of the research project and the correct use of the funds (Grant number: PI 17/00768). The funding body did not participate neither in the design of the study nor in the data analysis and manuscript elaboration. The trial sponsor is the La Paz Hospital Biomedical Research Foundation (fundacion.hulp@salud.madrid.org), which reviewed the study protocol.

\section{Availability of data and materials}

The datasheets and the manual for both interventions will be available from the corresponding author.

Ethics approval and consent to participate

The study was approved by the Research Ethics Committee of La Paz University Hospital, with the identifier 4911. Three amendments were made before final approval. Every participant will sign the Informed Consent form.

\section{Consent for publication}

Not applicable

\section{Competing interests}

The authors declare that they have no competing interests.

\section{Author details}

'Psychiatry and Mental Health Group, Hospital La Paz Institute for Health Research (IdiPAZ), Madrid, Spain. ${ }^{2}$ National University of Distance Education (UNED), Madrid, Spain. ${ }^{3}$ La Paz University Hospital, Madrid, Spain.

${ }^{4}$ Autonomous University of Madrid (UAM), Madrid, Spain. ${ }^{5}$ University of Alcala (UAH), Alcala de Henares, Spain. ${ }^{6}$ Mental Health Networking Biomedical Research Centre (CIBERSAM), Madrid, Spain. 
Received: 24 April 2019 Accepted: 8 July 2019 Published online: 29 July 2019

\section{References}

1. Baldwin P, Browne D, Scully PJ, Quinn JF, Morgan MG, Kinsella A, et al. Epidemiology of first-episode psychosis: illustrating the challenges across diagnostic boundaries through the CavanMonaghan study at 8 years. Schizophr Bull. 2005;31(3):624-38. https:// doi.org/10.1093/schbul/sbi025.

2. Welham JL, Thomis RJ, McGrath JJ. Age-at-first-registration for affective psychosis and schizophrenia. Schizophr Bull. 2004;30(4):849-53. https://doi. org/10.1093/oxfordjournals.schbul.a007137.

3. Lally J, Ajnakina O, Stubbs B, Cullinane M, Murphy KC, Gaughran F, et al. Remission and recovery from first-episode psychosis in adults: systematic review and meta-analysis of long-term outcome studies. Br J Psychiatry. 2017;211(6):350-8. https://doi.org/10.1192/bjp.bp.117.201475.

4. Leucht S, Winter-van Rossum I, Heres S, Arango C, Fleischhacker WW, Glenthøj B, et al. The optimization of treatment and management of schizophrenia in Europe (OPTiMiSE) trial: rationale for its methodology and a review of the effectiveness of switching antipsychotics. Schizophr Bull. 2015;41(3):549-58. https://doi.org/10.1093/schbul/sbv019.

5. Drake RJ, Nordentoft M, Haddock G, Arango C, Fleischhacker WW, Glenthø $B$, et al. Modeling determinants of medication attitudes and poor adherence in early nonaffective psychosis: implications for intervention. Schizophr Bull. 2015;41(3):584-96. https://doi.org/10.1093/schbul/sbv015.

6. Marshall M, Rathbone J. Early intervention for psychosis. Cochrane Database Syst Rev. 2011;(6):CD004718. https://doi.org/10.1002/14651858.CD004718.pub3.

7. Secher RG, Hjorthøj CR, Austin SF, Thorup A, Jeppesen P, Mors O, et al. Tenyear follow-up of the OPUS specialized early intervention trial for patients with a first episode of psychosis. Schizophr Bull. 2015;41(3):617-26. https:// doi.org/10.1093/schbul/sbu155.

8. Ruggeri M, Bonetto C, Lasalvia A, Fioritti A, de Girolamo G, Santonastaso P, et al. Feasibility and effectiveness of a multi-element psychosocial intervention for first-episode psychosis: results from the cluster-randomized controlled GET UP PIANO trial in a catchment area of 10 million inhabitants. Schizophr Bull. 2015;41(5):1192-203. https://doi.org/10.1093/schbul/sbv058.

9. Kuipers E, Holloway F, Rabe-Hesketh S, Tennakoon L. An RCT of early intervention in psychosis: Croydon outreach and assertive support team (COAST). Soc Psychiatry Psychiatr Epidemiol. 2004;39(5):358-63. https://doi. org/10.1007/s00127-004-0754-4.

10. Bello I, Lee R, Malinovsky I, Watkins L, Nossel I, Smith T, et al. OnTrackNY: the development of a coordinated specialty care program for individuals experiencing early psychosis. Psychiatr Serv. 2017;68(4):318-20. https://doi. org/10.1176/appi.ps.201600512.

11. Cotton SM, Filia KM, Ratheesh A, Pennell K, Goldstone S, McGorry PD. Early psychosis research at Orygen, the National Centre of excellence in youth mental health. Soc Psychiatry Psychiatr Epidemiol. 2016;51(1):1-13. https:// doi.org/10.1007/s00127-015-1140-0.

12. Amos A. Assessing the cost of early intervention in psychosis: a systematic review. Aust N Z J Psychiatry. 2012:46(8):719-34. https://doi.org/10.1177/ 0004867412450470.

13. Correll CU, Galling B, Pawar A, Krivko A, Bonetto C, Ruggeri M, et al. Comparison of early intervention services vs treatment as usual for early-phase psychosis: a systematic review, meta-analysis, and meta-regression. JAMA Psychiatry. 2018; 75(6):555-65. https://doi.org/10.1001/jamapsychiatry.2018.0623.

14. Bird V, Premkumar P, Kendall T, Whittington C, Mitchell J, Kuipers E. Early intervention services, cognitive-behavioural therapy and family intervention in early psychosis: systematic review. Br J Psychiatry. 2010;197(5):350-6. https://doi.org/10.1192/bjp.bp.109.074526.

15. Fleischhacker WW, Arango C, Arteel P, Barnes PRE, Carpenter W, Duckworth $\mathrm{K}$, et al. Schizophrenia--time to commit to policy change. Schizophr Bull. 2014;40(suppl3):165-94. https://doi.org/10.1093/schbul/sbu006.

16. Guloksuz S, van Os J. Renaming schizophrenia: $5 \times 5$. Epidemiol Psychiatr Sci. 2018:1-4. https://doi.org/10.1017/S2045796018000586.

17. Khoury B, Sharma M, Rush SE, Fournier C. Mindfulness-based stress reduction for healthy individuals: a meta-analysis. J Psychosom Res. 2015; 78(6):519-28. https://doi.org/10.1016/j.jpsychores.2015.03.009.

18. Gotink RA, Chu P, Busschbach JJ, Benson H, Fricchione GL, Hunink MG. Standardised mindfulness-based interventions in healthcare: an overview of systematic reviews and meta-analyses of RCTs. PLoS One. 2015;10(4): e0124344. https://doi.org/10.1371/journal.pone.0124344 eCollection 2015.
Review. (Retraction in: PLoS One. 2019;14(4):e0215608. doi: 10.1371/journal. pone.0215608)

19. Goldberg SB, Tucker RP, Greene PA, Davidson RJ, Wampold BE, Kearney DJ, et al. Mindfulness-based interventions for psychiatric disorders: a systematic review and meta-analysis. Clin Psychol Rev. 2018;59:52-60. https://doi.org/10.1016/j.cpr.2017.10.011.

20. Kabat-Zinn J. Full catastrophe living: the program of the stress reduction clinic at the University of Massachusetts Medical Center. New York: Delacorte Press; 1994.

21. Chadwick P. Mindfulness for psychosis. Br J Psychiatry. 2014;204:333-4. https://doi.org/10.1192/bjp.bp.113.136044.

22. MacDougall AG, Price E, Vandermeer MRJ, Lloyd C, Bird R, Sethi R, et al. Youth-focused group mindfulness-based intervention in individuals with early psychosis: a randomized pilot feasibility study. Early Interv Psychiatry. 2018:1-6. https://doi.org/10.1111/eip.12753.

23. Healey KM, Bartholomeusz CF, Penn DL. Deficits in social cognition in first episode psychosis: a review of the literature. Clin Psychol Rev. 2016;50:108-37. https://doi.org/10.1016/j.cpr.2016.10.001.

24. Fett AK, Viechtbauer W, Dominguez MD, Penn DL, van Os J, Krabbendam L. The relationship between neurocognition and social cognition with functional outcomes in schizophrenia: a meta-analysis. Neurosci Biobehav Rev. 2011;35(3):573-88. https://doi.org/10.1016/j.neubiorev.2010.07.001.

25. Chan AW, Tetzlaff JM, Altman DG, Dickersin K, Moher D. SPIRIT 2013: new guidance for content of clinical trial protocols. Lancet. 2013;381(9861):91-2. https://doi.org/10.1016/S0140-6736(12)62160-6 Epub 2013 Jan 8.

26. Calvert M, Kyte D, Mercieca-Bebber R, Slade A, Chan AW, King MT, et al. Guidelines for inclusion of patient-reported outcomes in clinical trial protocols: the SPIRIT-PRO extension. JAMA. 2018;319(5):483-94. https://doi. org/10.1001/jama.2017.21903.

27. Schulz KF, Moher D, Altman DG. CONSORT 2010 comments. Lancet. 2010; 376(9748):1222-3. https://doi.org/10.1016/S0140-6736(10)61879-X.

28. Combs DR, Adams SD, Penn DL, Roberts D, Tiegreen J, Stem P. Social cognition and interaction training (SCIT) for inpatients with schizophrenia spectrum disorders: preliminary findings. Schizophr Res. 2007;91(1-3):112-6.

29. Kabat-Zinn J, Massion AO, Kristeller J, Peterson LG, Fletcher KE, Pbert L, et al. Effectiveness of a meditation-based stress reduction program in the treatment of anxiety disorders. Am J Psychiatry. 1992;149(7):936-43 Available from: https://s3.amazonaws.com/academia.edu.documents/46 988796/Effectiveness_of_a_Meditation-based_Stre20160703-30744-11u72g7. pdf?AWSAccessKeyld=AKIAIWOWYYGZ2Y53UL3A\&Expires=155557594 9\&Signature=MOkSjB5g2bZrS9psXZ8rLyiH6kY\%3D\&response-contentdisposition=inline\%3B\%20filename\%3DEffectiveness_of_a_meditationbased_stre.pdf.

30. Segal ZV, Teasdale JD, Williams JM. Mindfulness-based cognitive therapy for depression. New York: The Guildford Press; 2013.

31. Germer CK, Neff KD. Self-compassion in clinical practice. J Clin Psychol. 2013;69(8):856-67. https://doi.org/10.1002/jclp.22021.

32. Van Gordon W, Shonin E, Garcia-Campayo J. Are there adverse effects associated with mindfulness? Aust N Z J Psychiatry. 2017;51(10):977-9. https://doi.org/10.1177/0004867417716309.

33. Morosini PL, Magliano L, Brambilla L, Ugolini S, Pioli R. Development, reliability and acceptability of a new version of the DSM-IV social and occupational functioning assessment scale (SOFAS) to assess routine social functioning. Acta Psychiatr Scand. 2001;101(4):323-9. https://doi.org/10.1 034/j.1600-0447.2000.101004323.x.

34. Garcia-Portilla MP, Saiz PA, Bousoño M, Bascaran MT, Guzmán-Quilo C, Bobes J. Validación de la versión española de la escala de Funcionamiento Personal y Social en pacientes ambulatorios con esquizofrenia estable o inestable. Rev Psiquiatr Salud Ment. 2011;4(1):918. https://doi.org/10.1016/j.rpsm.2010.11.003.

35. American Psychiatric Association. Diagnostic and statistical manual of mental disorders (4th ed., Text Revision). Washington, DC: Author; 2000

36. Bobes J, García-Portilla MP, Bascarán MT, Saiz PA, Bousoño M. Banco de instrumentos básicos para la práctica de la psiquiatría clínica. [CD-ROM]. 2a Edición. [Bank of Instruments for the Clinical Practice (CD-ROM). 2nd Edition]. Ars Medica: Barcelona; 2002.

37. Mike S. C. JM, sue B. the concurrent validity of the global assessment of functioning (GAF). Br J Clin Psychol. 2010;41(4):417-22. https://doi.org/1 $0.1348 / 014466502760387533$

38. Kay SR, Fiszbein A, Opler LA. The positive and negative syndrome scale (PANSS) for schizophrenia. Schizophr Bull. 1987;13(2):261-76. https://doi. org/10.1093/schbul/13.2.261. 
39. Kay SR, Fiszbein A, Vital-Herne M, Silva FL. The positive and negative syndrome scale - Spanish adaptation. J Nerv Ment Dis. 1990;178:510-7 Available from: https://journals.lww.com/jonmd/Citation/1990/08000/The_ Positive and Negative Syndrome Scale_Spanish.7.aspx.

40. Addington D, Addington J, Maticka-Tyndale E. Assessing depression in schizophrenia: the Calgary depression scale. Br J Psychiatry. 1993;163(Suppl. 22): 39-44 PMID: 8110442

41. Sarró S, Dueñas RM, Ramírez N, Arranz B, Martínez R, Sánchez JM, et al. Crosscultural adaptation and validation of the Spanish version of the Calgary depression scale for schizophrenia. Schizophr Res. 2004;68(2-3):349-56. https:// doi.org/10.1016/S0920-9964(02)00490-5.

42. Beck AT, Epstein N, Brown G, Steer RA. An inventory for measuring clinical anxiety: psychometric properties. J Consult Clin Psychol. 1988; 56(6):893-7 PMID: 3204199.

43. Sanz J, Navarro ME. Propiedades psicométricas de una versión española del Inventario de Ansiedad de Beck (BAI) en estudiantes universitarios [psychometric propierties of a Spanish version of Beck anxiety inventory in university students]. Ansiedad y Estrés. 2003;9:59-84 Available from: https:// dialnet.unirioja.es/servlet/articulo?codigo $=623810$.

44. Sanz J, Garcia-Vera MP, Fortun M. El "Inventario de Ansiedad de Beck" (BAl): Propiedades psicométricas de la versión española en pacientes con trastornos psicológicos [Beck Anxiety Inventory (BAl): Psychometric properties of the Spanish versión in a simple of patients with psychological disorders]. Behav Psychol. 2012;20(3):563-83 Available from: https://www. researchgate.net/profile/Jesus_Sanz4/publication/286536823_THE_BECK_ ANXIETY_INVENTORY_BAI_psychometric_properties_of_the_Spanish_ version_in_patients_with_psychological_disorders/links/596bae01458515 e9afb1cb24/THE-BECK-ANXIETY-INVENTORY-BAI-psychometric-properties-ofthe-Spanish-version-in-patients-with-psychological-disorders.pdf.

45. Spearing MK, Post RM, Leverich GS, Brandt D, Nolen W. Modification of the clinical global impressions (CGI) scale for use in bipolar illness (BP): the CGlBP. Psychiatry Res. 1997;73:159-71. https://doi.org/10.1016/S0165-1781 (97)00123-6.

46. Corcoran R, Mercer G, Frith CD. Schizophrenia, symptomatology and social inference: investigating "theory of mind" in people with schizophrenia. Schizophr Res. 1995;17(1):5-13. https://doi.org/10.1016/0920-9964(95)00024-G.

47. Janssen I, Krabbendam L, Jolles J, Van Os J. Alterations in theory of mind in patients with schizophrenia and non-psychotic relatives. Acta Psychiatr Scand. 2003;108(2):110-7. https://doi.org/10.1034/j.1600-0447.2003.00092.x.

48. Baron-Cohen S, Jolliffe T, Mortimore C, Robertson M. Another advanced test of theory of mind: evidence from very high functioning adults with autism or Asperger syndrome. J Child Psychol Psychiatry. 1997;38(7):813-22. https:// doi.org/10.1111/j.1469-7610.1997.tb01599.x.

49. Baron-Cohen S, Wheelwright S, Hill J, Raste Y, Plumb I. The "Reading the mind in the eyes" test revised version: a study with normal adults, and adults with Asperger syndrome or high-functioning autism. J Child Psychol Psychiatry Allied Discip. 2001;42(2):241-51. https://doi.org/10.1080/13546 805.2012.721728.

50. Gil D, Fernández-Modamio M, Bengochea R, Arrieta M. Adaptation of the hinting task theory of the mind test to Spanish. Rev Psiquiatr y Salud Ment. 2012;5(2):79-88. https://doi.org/10.1016/j.rpsmen.2011.11.002.

51. Browne J, Penn DL, Raykov T, Pinkham AE, Kelsven S, Buck B, et al. Social cognition in schizophrenia: factor structure of emotion processing and theory of mind. Psychiatry Res. 2016;242:150-6. https://doi.org/10.1016/j. psychres.2016.05.0341.

52. Fernández-Abascal EG, Cabello R, Fernández-Berrocal P, Baron-Cohen S. Testretest reliability of the "Reading the mind in the eyes" test: a one-year followup study. Mol Autism. 2013;4(1):2-7. https://doi.org/10.1186/2040-2392-4-33.

53. Kohler CG, Turner TH, Bilker WB, Brensinger CM, Siegel SJ, Kanes SJ, et al. Facial emotion recognition in schizophrenia: intensity effects and error pattern. Am J Psychiatry. 2003;160(10):1768-74. https://doi.org/10.1186/204 0-2392-4-33.

54. Gil-Sanz D, Fernández-Modamio M, Bengochea-Seco R, Arrieta-Rodríguez M, González-Fraile E, Pérez-Fuentes G, et al. PERE: Una nueva herramienta para valorar el reconocimiento de las emociones básicas y su aplicación en la esquizofrenia. Rev Psicopatol y Psicol Clin. 2017;22(2):85-93. https://doi.org/1 0.1186/2040-2392-4-33

55. Combs DR, Penn DL, Wicher M, Waldheter E. The ambiguous intentions hostility questionnaire (AIHQ): a new measure for evaluating hostile socialcognitive biases in paranoia. Cogn Neuropsychiatry. 2006;12(2):128-43. https://doi.org/10.1080/13546800600787854.
56. Brown KW, Ryan RM. The benefits of being present: mindfulness and its role in psychological well-being. J Pers Soc Psychol. 2003;84(4):822-48. https:// doi.org/10.1037/0022-3514.84.4.822.

57. Soler J, Tejedor R, Feliu-Soler A, Pascual JC, Cebolla A, Soriano J, et al. Psychometric proprieties of Spanish version of mindful attention awareness scale (MAAS). Actas Españolas Psiquiatr. 2012;30(1):19-26. https://doi.org/1 $0.1063 / 1.4993410$

58. Neuctherlein KH, Green MF. MATRICS consensus cognitive battery (Spanish version). California: The Regents of the University of California; 2009.

59. Crane RS, Eames C, Kuyken W, Hastings RP, Williams JMG, Bartley T, et al. Development and validation of the mindfulness-based interventions teaching assessment criteria (MBI:TAC). ASMNT. 2013;20(6):681-8. https://doi. org/10.1177/1073191113490790.

60. Kyte D, Ives J, Draper H, Calvert M. Current practices in patient-reported outcome (PRO) data collection in clinical trials: a cross-sectional survey of UK trial staff and management. BMJ Open. 2016;6(10):e012281. https://doi. org/10.1136/bmjopen-2016-012281.

61. Cook JA, Julious SA, Sones W, Hampson LV, Hewitt C, Berlin JA, et al. DELTA2 guidance on choosing the target difference and undertaking and reporting the sample size calculation for a randomised controlled trial Suzie Cro. Trials. 2018;19(1):1-8. https://doi.org/10.1186/s13063-018-2884-0.

62. May R. Relating to alternative realities. In: Romme M, Escher S, editors. Psychosis as a personal crisis: an experience-based approach. New York and London: Routledge; 2012. p. 140-52.

\section{Publisher's Note}

Springer Nature remains neutral with regard to jurisdictional claims in published maps and institutional affiliations.
Ready to submit your research? Choose BMC and benefit from:

- fast, convenient online submission

- thorough peer review by experienced researchers in your field

- rapid publication on acceptance

- support for research data, including large and complex data types

- gold Open Access which fosters wider collaboration and increased citations

- maximum visibility for your research: over $100 \mathrm{M}$ website views per year

At BMC, research is always in progress.

Learn more biomedcentral.com/submissions 